\title{
Wireless Smart Sensor Networks for Real-Time Warning System of Flash Floods and Torrents in KSA
}

\author{
Hattab Guesmi \\ Faculty of Science and Arts in Addayer, \\ Jazan university, KSA
}

\begin{abstract}
The dangers of torrents and floods that taken place repeatedly in many countries of the world, Saudi Arabia is one of them, are impossible to be fully prevented or controlled. But it is possible to limit its effects and minimize its losses. That's by defining the endangered places and sitting suitable maps for them as well as conducting researches and studies that enhance the real-time flash flood forecasting and monitoring. So that, practical researches and studies are required specifically which can predict the risk before it happens to reduce its harms and damages and save humans and their properties. In this research, we will propose a wireless sensor networks for real-time flood monitoring and warning system. The real-time flood monitoring system based on wireless smart sensors measure hydrological data and capture remote images. The system determine the expected reaching time, affected zones and danger intensity based on hydrological and geographic models then it automatically launches the warning processes. This system warn people for the sudden torrents and their expected dangers in order to take the necessary safety procedures against its risks. That leads to save people and their properties and reduce the human and material losses that may occur. Warning process starts on the suitable time before disaster happens.
\end{abstract}

\section{Keywords}

WSN, EWS, flash flood, forecast, Alert system

\section{INTRODUCTION}

Floods disasters are responsible for the loss of precious lives and destruction of large amounts of property every year, especially in the poor and developing countries. A lot of effort has been put in developing systems which help to minimize the damage through early disaster predictions. This reinforces the ways to prevent and reduce human and material losses through the activation of the means of early warning systems. Early warning system provides an effective solution by giving people sufficient time to evacuate and protect their property from the danger. Timely report and response are especially important for reducing the number of sufferers and damages. In such cases, the communication structure that may not function well, this makes it hard to gain information about the incident, and then to respond to the incident rapidly and properly. Smart sensor networks can provide a good solution to these problems through actively monitoring and well-timed reporting emergency incidents to base station.

KSA is characterized by distinct climatic regions, due to high spatial and temporal temperature variability. According to the Köppen classification the major parts of SA are hot and dry $[1,2]$, where precipitation is infrequent and temperature is high. The precipitation in most areas of the SA is scarce, infrequent, and generally falling from October through April. Throughout other months, there is almost no precipitation with the exception of the southwestern region of Saudi Arabia. However, the southwestern area of the SA is classified as semi-arid. The spatial variation of the precipitation in the southwestern region is high due to mountainous regions. The southwestern region of SA is characterized by rainfall events during the entire year due to the topographically driven convective rain. The annual total precipitation in the north of this region ranges from 50 to 100 $\mathrm{mm}$ happening principally through the wintertime. In this semi-arid region, only a few precipitation events are sufficient to produce this amount. The area of Asir and higher mountain of Jazan are subject to Indian monsoons, ordinarily happening among October and March. During this period, an average of 300 millimeters of precipitation occurs, approximately $60 \%$ of the annual total. Additionally, condensation caused by the slopes of higher mountain participates to the total rainfall in Asir and the southern Hijaz. Direct interaction of the moist westerly flow and the slopes of the mountains contribute to the total rainfall [3, 4]. Despite rareness of intensive and frequent rainfall events over Kingdom of Saudi Arabia (KSA); an arid/semi-arid region, occasional flash floods occur and result in large amounts of damaging surface runoff. Regions with plentiful rainfall, as well as arid and semi-arid regions, are equally vulnerable to flash floods. A floodpreventing protection plan should start from the mountainous regions in order to moderate the phenomenon in its generation. In the high regions, where a sudden increase of torrent kinetic energy may appear, the flood phenomenon has not yet begun. This is where the main volume of water is collected before it proceeds to the low regions. Technical measures, such as tanks and inhibitory dams, can be constructed for the interception of the flood. Such measures can assist with. the time desynchronization of the water accumulation at points where the kinetic energy of the torrent is increased, and, consequently, can decrease the rate of the kinetic energy release. This can be achieved only if the technical measures are well-designed and strategically located considering the basin hydrology. By tracking data like rainfall, ground saturation, and upstream water levels, industries and utilities can get early warnings about flooding and take action to protect their customers and equipment.

A flood warning system incorporates telemetered rainfall and flow/water level data measured at various locations in the prevented area with remote measurement images. Real-time accurate data collection is required for this use, and smart sensor networks improve the system capabilities and their role in early warning communities of torrents and flash flooding disasters, which is a good solution of significantly reducing the damage, health-risks and financial impact of events. Even the best forecast quality is useless if the system does not communicate the proper information to the right people. Early warning information empowers people to take action prior to a disaster. Early warnings may be disseminated to targeted 
users (local early warning applications) or broadly to communities, regions or to media

This work proposed an early warning model based on smart Wireless Sensor Networks to predict torrents and flash flooding using simple and fast calculations to provide realtime results and save the lives of people who may be affected by the flood. The early warning system covers a range of smart sensors including sensors to measure the amount of rain, the height of the water level in the valleys and the torrent velocity. In addition to that, sensors node gather all the information and process it to the controller in order to determine the arrival time, affected zone and the danger degree of the disaster which will be sent to people and to the civil defense.

\section{RELATED WORKS}

Abdelkader et all in [5] proposed a flood sensing system based on Unmanned Aerial Vehicles (UAVs) releasing disposable Lagrangian microsensors. Among all possible systems, UAVs (Unmanned Aerial Vehicles) are the most adapted to the sensing of floods in large geographical areas around cities in desert environment. Victor Seal et all [6] designed a forecasting model using Wireless Sensor Networks to predict flood in rivers using simple and fast calculations to provide real-time results. Their prediction model uses multiple variable robust linear regression to provides real time predictions with reliable accuracy, thus having features which are desirable in any real world algorithm. When the water level rises, they represent it using a polynomial whose nature is used to determine if the water level may exceed the flood line in the near future. Rafael Marin-Perez et all [7]describe the design, development, and deployment of a real-time monitoring system for hydrological applications (flood monitoring) in a flash-flood prone $650 \mathrm{~km}^{2}$ semiarid watershed in Southern Spain. A developed low-power and long-range communication device, provides automatic data gathering and reliable transmission. Saysoth Keoduangsine [8] describes how to collect and transmit timely hydrological data using GPRS (General Pocket Radio Service) via a mobile phone network from remote hydrological stations to the data center in the case of the Lower Mekong River Basin (LMRB) for Flood Warning System. AlHassoun in [9] has developed an empirical formulae to estimate rainfall intensity in Riyadh region. Samman in [10] proposed a numerical simulation diagnostics of a flash flood event in Jeddah, Saudi Arabia. Alfieri et all in [11] has studied the ensemble hydrometeorological simulation for flash flood early detection in southern Switzerland. Also, flash flood warnings using the ensemble precipitation forecasting technique is applied in the study on forecasting floods in Taiwan caused by typhoons was developed by Yang et all in [12]. Jamil et all in [13] Applied water and rain information analysis of monitoring and early warning system of mountain torrent. The monitoring system of water and rain information mainly includes network layout of water and rain monitoring station, information acquisition, information transmission and communication networking. Real-Time Flash-Flood Monitoring, alerting and forecasting system using data mining and Wireless sensor network by Mane et all in [14]. The system not only measures river water level and different weather conditions such as temperature, humidity and vibration through wireless sensor nodes but also it can forecast possibility of future disasters by using data mining algorithm based on a database. Some operational early warning system for surface water flooding and flash floods rely on simplified indexes based on the concept of extreme conditions, with no need for additional calibration parameters are presented in $[15,16,17,18,19]$. Visual sensing method for urban flood monitoring are used in $[20,21]$ as a solution for early warning system. Image-based automated monitoring of flood formation and analyses of water level fluctuation were proposed as value-added intelligent sensing applications to turn a passive monitoring camera into a visual sensor. Whereas visual sensors can acquire dynamic image information of monitored sites and provide disaster prevention agencies with actual field information for decision-making to relieve flood hazards.

Our proposed work is to combine with the visual sensing method traditional hydrological monitoring cameras and hydrological sensor have the ability to sense and analyze the local situation of flood events. This can solve the current problem that flood monitoring heavily relies on continuous manned monitoring based on complex hydrological and geographic models.

\section{STUDY OF FLASH FLOOD AND TORRENTS IN KSA}

Based on the TRMM (Tropical Rainfall Measuring Mission) data [22], the seasonal precipitation distributions in KSA shows that spring is the highest $(38.93 \%)$ and winter is the second highest $(32.51 \%)$ as precipitation occurring seasons. These contribute significantly towards the large quantities of precipitation, which happen through the wet season (November to May, $75.39 \%$ ) over all the regions of SA. Only small quantities of rain are observed through the summer $(11.46 \%)$, and (12.94) in the dry season (from June to September) while autumn received about $17.09 \%$ of the total annual precipitation. The SW region receives rain in all seasons, with a maximum in spring $(44.29 \%)$, while the NW and NE regions receive very small quantities of precipitation in summer season $(\sim 2 \%)$. The SE region is almost totally dry. In general, precipitation increases with higher altitude, at a rate of $\sim 1.93 \mathrm{~mm} / \mathrm{m}$ in SA. This is especially true in the western part of the SA and along the Red Sea coastal areas, where adjacent to the Tihamah, the rather flat coastal area about $50 \mathrm{~km}$ in width, there is a sharply rising mountain chain that reaches elevations greater than $1500 \mathrm{~m}$, especially in the north where the Hijaz Mountains lie [2]. Due to the different morphological units in the western part of the SA, Tihamah, foothills, and mountains, the climate recording stations were lumped according to their location and related to one of these three morphological units. Other towering stations for instance, Al-Baha, Taif, Abha and KhamisMushait receive great quantities of precipitation. Gizan altitude is only $4 \mathrm{~m}$ above mean sea level, but it receives a large quantity of precipitation. It is situated on the windward side of the southwest tip, through which precipitation systems shift to SA throughout both the wet and the dry seasons [23].

Rain storms are highly hazardous to higher mountain urbanized areas as they usually develop with locally extreme rainfall rates which outweigh the soil infiltration capacity and the urban drainage potential, causing surface water flooding or flash floods. Those events occur on time scales ranging from minutes to few hours and typically affect limited areas up to few hundreds of square kilometers. The mountain torrent disaster burst out frequently and one of the most important reasons is rainstorm. Past flood events in KSA gathered from the International Disaster Database [23] are presented in Table 1. The main characteristic of flash floods and surface water flooding is their extremely sudden onset, resulting in very short warning times before an event. Although meteorological warning systems are widespread tools available at the majority of national meteorological 
services across KSA, most of them have a space-time resolution rather coarse for a reliable prediction of surface water flooding and flash floods. The most common approach consists in comparing the latest rainfall forecasts, from numerical weather predictions, with reference thresholds often derived by statistical analysis on long term records of point measurements. The lag due to the hydrological processes involved is often too short for the implementation of effective warning procedures, as the hazard usually takes place in the same area where the rain storm occurs.

Table 1. Major flood events in KSA between 1964 and 2015 [23]

\begin{tabular}{|c|c|c|}
\hline \multicolumn{2}{|c|}{ Date } & \multirow{2}{*}{$\begin{array}{l}\text { Location in } \\
\text { KSA }\end{array}$} \\
\hline Start & End & \\
\hline 4 April 1964 & 4 April 1964 & Najran \\
\hline $\begin{array}{l}24 \text { December } \\
1985\end{array}$ & $\begin{array}{l}24 \text { December } \\
1985\end{array}$ & North West \\
\hline 8 April 2002 & 13 April 2002 & Makkah \\
\hline $\begin{array}{l}11 \text { November } \\
2003\end{array}$ & $\begin{array}{l}11 \text { November } \\
2003\end{array}$ & Makkah \\
\hline 8 Aug 2003 & 12 Aug 2003 & Jizan \\
\hline 14 April 2004 & 16 April 2004 & Jizan \\
\hline 28 April 2005 & 28 April 2005 & Assir, jeddah \\
\hline 22 January 2005 & 27 January 2005 & Medinah \\
\hline $\begin{array}{l}24 \text { November } \\
2009\end{array}$ & $\begin{array}{l}26 \text { November } \\
2009\end{array}$ & Jeddah, Makkah \\
\hline 10 July 2010 & 12 July 2010 & Najran \\
\hline 23 july 2010 & 25 july 2010 & Assir, Jizan \\
\hline 25 January 2011 & 31 January 2011 & Jeddah \\
\hline 14 April 2012 & 18 April 2012 & Western Regions \\
\hline 2 May 2013 & 2 May 2013 & Bicha \\
\hline $\begin{array}{l}16 \text { November } \\
2013 \\
\end{array}$ & $\begin{array}{l}\text { 19 November } \\
2013\end{array}$ & Riyadh \\
\hline $\begin{array}{l}17 \text { November } \\
2015\end{array}$ & $\begin{array}{l}18 \text { November } \\
2015\end{array}$ & Jeddah \\
\hline
\end{tabular}

\section{FLASH FLOOD AND TORRENTS EARLY WARNING SYSTEM CHALLENGE}

Flash floods is the result of a recurring situation of an extreme rainfall events in the affected area, which may also induce severe torrents flooding downstream, possibly in different neighboring areas. Those events occur on time scales ranging from minutes to few hours and typically affect limited areas up to few hundreds of square kilometers. The mountain torrent disaster burst out frequently and one of the most important reasons is rainstorm. The time between the beginning of precipitation and the threshold exceedence is the maximum potential warning time. During the responsewarning time, the threat is recognized and actions such as data collection, evaluation, notification and decision making take place. During the mitigation time, efforts are made to prevent hazards from developing into flood disasters, or to reduce the effects of the flood. The Trends and challenges of recent systems natural disasters requires the conception of multihazard warning systems which operates on large supernational domains. Alert Systems need to focus more on improving the visualization platforms and the dissemination of information for alert situations. In fact, increasing the quality of data and availability, models and computing facilities leads to a growth of the communicated information [22, 23]. Early warning system critical and communicated information should include severity and probability of exceeding fixed warning thresholds, potential damage and affected population, location, hazard type, expected onset and duration. The integration of alert maps is a required practice in many operational systems, with additional information about selected zones leads to a complete alert information. [24, 25]. Gathered information needs to be well structured and efficiently carried in an easy and understandable way. The overflow of information is important to the system performance and adds up to negative effects of stress on decision-making under time pressure. Finally, large effort needs to be put into training all stakeholders on emergency procedures and safety measures following official alerts [26].

This research aims to set up an early warning system for the prevention of catastrophic floods and torrents in Saudi Arabia. In current early warning system in KSA, numerical weather predictions are the main input to most systems, because they simulate the evolution of weather conditions in the future, and they are accessible and on large domains, which leads to an early preparedness and a possible reduction of the damage caused by flash floods. However, some limitations can exist in applying numerical weather predictions for operational alert systems. Firstly, small scale phenomena such as local rainfall peaks can produce surface water flooding, and flash floods, however, the resolution of most available numerical weather predictions gives only extreme features will be shown on space-temporal scales. Besides, fine resolution numerical weather predictions have wide uncertainty ranges, so results from deterministic estimates often lead to poor performance. Secondly, The simulation of sets of possible realizations of the system state is useful to derive information on the prediction uncertainty and proves most beneficial for longer forecast lead times. Current trends in flash flood early warning system denote an increasing use of ensemble weather predictions as one important input data [27, 28]. As a consequence, early warning systems for such events remain a scientific challenge, a possible solution is to establish an early warning system based on numerical weather predictions. Nevertheless, flood risk mapping is used for large-scale risk assessment, which is not specific or conducted in real time for urban local-scale assessment. In addition, it is difficult to verify the analysis results with the actual runoff status of the streets. Thus, this method remains insufficient for enabling decision-makers to conduct immediate and accurate disaster reduction actions. The installation of telemetric meteorological and geographic information stations in the studied area is essential for a successful flood forecastingwarning system. Meteorological and geographic data have to be recorded in real time. The collected information is the input for the hydrological-hydraulic modeling that early warning flood events. We can also use drone or UAV (Unmanned aerial vehicle ) to record real time metrological information for affected zones such as water level, images and videos $[29,30]$. An early warning system is the correct action taken by individuals in the correct time to avoid or reduce the disaster risk and prepare for effective response based on the provision of timely and efficient information. It consists of four main parts:

- Risk assessment: early warning system provides essential and efficient information to set priorities for mitigation and prevention strategies from;

- Monitoring and predicting: systems should monitor the disaster and provide timely estimates and the degree of the potential risk faced by communities and environment;

- Disseminating information: systems should deliver warning messages to the potentially affected locations to alert local and regional governmental agencies and 
indicate the emergemcy locations for each affected zone. The messages should be reliable, synthetic and simple to be understood by the public and authorities.;

- Response: the critical aspects of disaster mitigation in an effective early warning system are a challenge key of good governance, coordination, appropriate action plans and public awareness and education..

Failure of any part of the system will imply failure of the whole system. For example, accurate warnings will have nonimpact if the population is not prepared or if the alerts are received but not disseminated by the agencies receiving the messages.

\section{MODEL PROPOSITION}

The proposed Flash Flood model analysis uses, hydrological data such as water level, water velocity and precipitation gathered from monitoring stations combined with remote measurement images and geographic models to analyze and simulate flood events. This analysis extracts risk information from a prediction viewpoint, which can be estimated with regard to different scenarios such as potential flood danger degree and geographic area that will be flooded, then it prepare in advance flood risk assessment and risk mapping to identify zones that are vulnerable to flooding. The advance acquisition of flood risk assessment information, such as the flooding probability, degree, location, and height is very important for flood management and policy implementation that enables implement disaster management practices in advance. Moreover, results given by flash flood model analysis can be used to reduce the disaster, for example based on the results of flood analysis if urban relief the civil defense can determine and setup the operational regimes or install valves and pump stations for flood discharge $[31,32,33]$.

\subsection{Proposed flood telemetered sensing method}

\subsubsection{Rainfall data}

The rainfall sensor detects the amount and intensity of rain in the studied zone. We have installed wireless rain gauge sensor network in the studied zone to collect the rainfall accumulation and the rainfall rate. The quality of any flood forecast depends to a high degree on the quality of the rainfall input. A wide and efficient rain gauge networks provide important calibration and validation data and can even be used to setup warning levels. However, a rain gauge networks only is not able to provide a proper weather forecast and predict flood events[34].

\subsubsection{Flow water data}

The velocity of the water has an important impact to determine the degree of dangerous in flash flood event. We have installed sensors that gather information about the torrent velocity in different places then to send collected data to the local station. We have used a model to analyze and interpret theses information to take decision about the early warning system. The flow sensor is a device for observing and recording the rate of fluid flow [35].

\subsubsection{Water level data}

Level sensors are used for the measurement of the level of the water above a pre-set reference in the valley or in the studied zone (wadi). Water level indicates that if the water exceeds the threshold level. The impact of a flood that raises the water level exceed the threshold level is very dependent on the slopes of the valley $[36,37]$.

\subsubsection{Temperature sensor}

A temperature sensor detect the hotness and the coldness of the environment. The sensing of the temperature can be done with the directly contact or an indirect contact. The temperature sensor thermocouple is used to measure the temperature of the environment accurately. Thermocouple sensor is connected to the programmable node in which the voltage output is directly proportional to the environment temperature.

\subsubsection{Flood Visual Sensor}

In most models based on hydrological data only it is difficult for decision-makers to clearly understand the field flood situation, the decisions made might inevitably be unsuitable in the actual situation. Therefore, real-time images provide more useful dynamic field information to predict the flood behavier and support improved decisions from disaster management controller in optimizing their emergency responses at the best time for each zone [38, 39]. Although the use of remote sensing images can overcome the in situ gauge measurement's disadvantage of incomprehensive flood monitoring and can reach decimeter-level accuracy for water level measurement, it can realize long-term continual monitoring of urban small-scale flood events and accurately measure the water level changes in small rivers. Moreover remote sensing image can quantitate flow dynamics, such as river flood discharge or overflow, it provides dynamic information regarding the actual spatial change in runoff, such as floodplain flow and bank overflow. We have used a camera sensor for remote sensing technologies for defining flooded area.

\subsubsection{Alert systems}

Information and communication technology (ICT) is a key element in early warning systems, which plays an important role in disaster control and management and disseminating information to organizations in charge of responding to warnings and to the people during and after a disaster. Many communication tools are currently available for warning dissemination, such as Short Message Service (SMS), email, radio, TV and web service. [40, 41, 42, 43]. Real-time warning systems have two main components:

- Reliability and robustness of Communication infrastructure hardware especially during the disaster;

- Efficient and suitable interactions between the main actors such as stakeholders, decision makers, public, and media in responding to an early warning alert.

\subsection{The proposed architecture for the early warning system}

The proposed architecture of WSNs are deployed using an approach that groups nodes communicating over short distance together with some nodes capable of communication over a wider range. WSN nodes communicate only with neighboring nodes to reduce the transmission power and losses, thus eliminating the need for expensive repeaters and transmitters used in traditional telemetry systems. Short range communicating node in a WSN can act as a data acquisition device or data router and wide range communication node can act as a router or a data aggregator. This architecture maximizes the reliability of the whole flash flood monitoring system. This model uses a combined model composed of the 
centralized model and the distributed model. This model aims to partly combine the advantages of both the above systems and simultaneously, cancel out the disadvantages of either system by combining both. Though the network hierarchy remains the same here as in the previous cases, computation is done on multiple nodes unlike the centralized method, and yet computation in almost all nodes is not done as in the distributed method. Thus, it is possible to bring about an appropriate balance of the cost of deployment and the redundancy and reliability of the system as needed $[44,45$, 46].

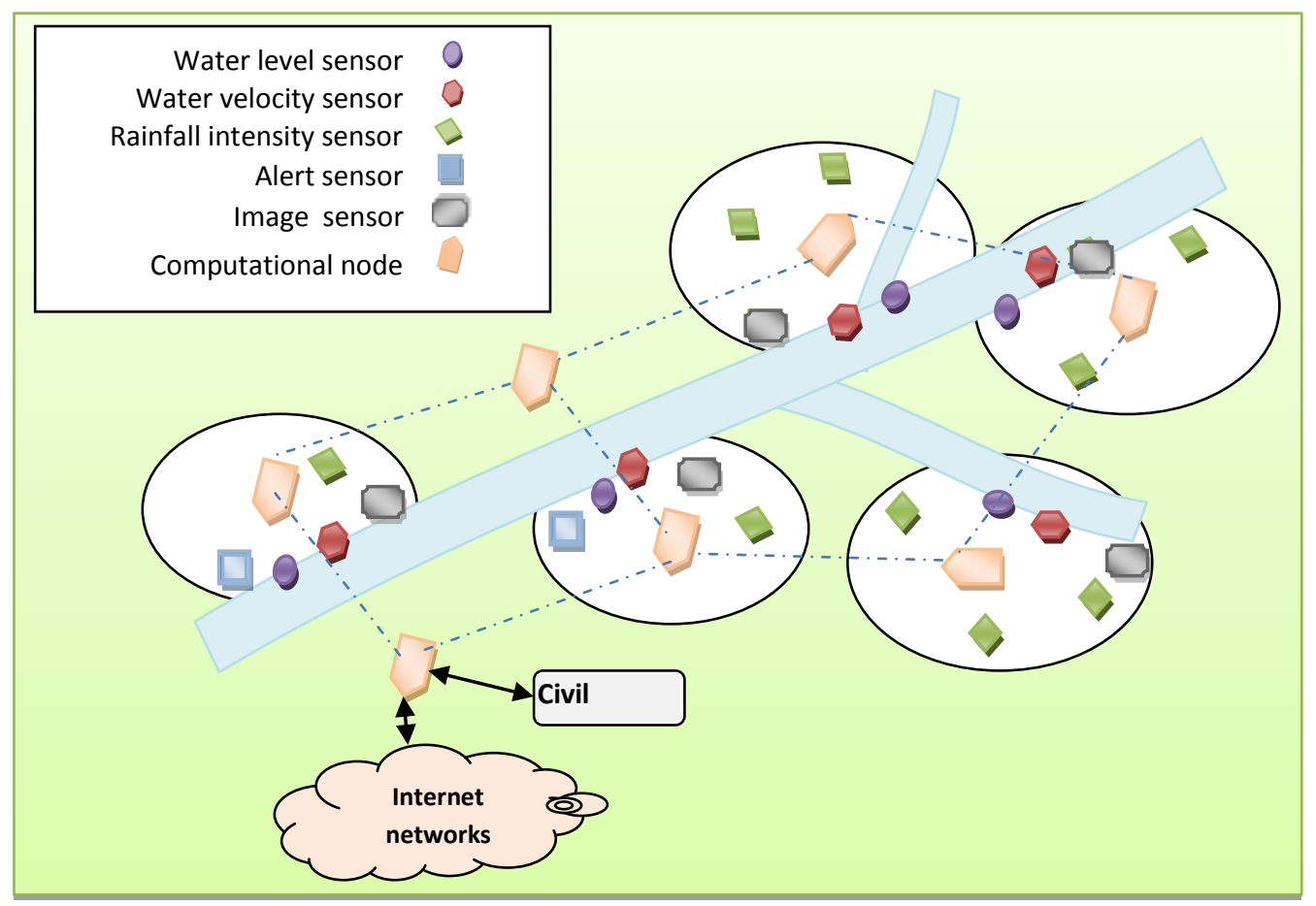

Fig 1. the architecture of the installed WSN for the EWS

The proposed WSN system architecture for flood forecasting presented in figure 1 consists of sensors which sense and collect the data relevant for calculations such as rain full intensity, water level and water velocity. Some nodes referred to as computational nodes that have large processing powers implement our proposed distributed prediction algorithm and will act as a manned central monitoring office. This node verifies the results with the available online information and implements a centralized version of the prediction algorithm as a redundancy mechanism, issues alerts and initiates evacuation procedures. Different types of sensors are required to sense water level, water velocity, rainfall, temperature, flood image, etc. Also, different actuators are required to alert whom in the affected zone. The WSN architecture of the proposed early warning system at site is given in Figure 1. As we can see the valley has been broken into several monitoring zones. In each zone, a sensor node collects data and sends them to its computational node. Data collection and localized prediction takes place at each computational node. The computational nodes then send the data to the central (office) node and also share it among themselves. The system consists of $\mathrm{M}$ number of wireless sensor nodes (WSNs) deployed at several locations along the valley bed of Jazan, KSA. Six nodes taken together constitute a group. The data collected by these sensors are used in the flood prediction algorithm. The computational nodes possess powerful CPUs required to implement the distributed prediction model and they are designed to communicate the prediction results to the monitoring node. They also have communication between themselves for detecting malfunctioning of nodes. The central node is connected to the IP network to launch the real time emergency alert. However it is important to include a manned central node in this whole process to raise the alarm and coordinate evacuation measures if needed. Intermediate nodes have to be deployed to ensure connectivity in case the central does not fall within the communication range of all the nodes to minimize the effect of a node failure while connecting the computational nodes to the central [47, 48]. A generic framework was adopted for creating and hosting the components of the proposed system which work according to a four-step cycle:

- Monitoring: data is collected in real time from sensors and fed to the central supervisory station and any other available type of weather information.

- Analysis: apply applications/workflows for early warning system to perform analysis of sensor data streams, such as simulation based on hydrological and geographic models..

- Performance analysis: the outcome of this analysis is judged according to the proposed rules in order to estimate the risk level and determine the necessity of taking action.

- Action taken: based on the value judgment, the system sends alert messages to the Defense civil in order to recommend actions for users interacting with a decision support system, and automatically take action to warn affected areas. 


\section{EXPERIMENTAL STUDY}

The early warning system covers a range of smart sensors including sensors to measure the amount of rain, the height of the water level in the valleys and the torrent velocity. In addition to that, sensors node gather all the information and process it to the controller in order to determine the arrival time and the danger degree of the disaster which will be sent to the civil defense. The proposed system incorporates telemetered rainfall and flow/water level data measured at various locations in the prevented area. Real-time accurate data collection is required for this use, and smart sensor networks improve the system capabilities and their role in early warning communities of torrents and flash flooding disasters, which is a good solution of significantly reducing the damage, health-risks and financial impact of events. So we have placed a simulation platform based WSN using LabView as a simulation tool and we have gathered all required information and parameters to setup scenarios of simulations for an early warning system for flood torrents and valleys. The design of the data processing system was based on the cRIO data acquisition system and on the LabView programming software. The proposed system also possesses a web application for supervising all of the equipment and for automating the processing, management, and analysis of all recorded information. The architecture of the developed system was designed to be easily scalable and configurable. The acquisition of data for the flash flood was performed through virtual instruments (VI) developed with the NI LabView graphical programming tool and operating in realtime on the cRIO chassis. The practical implementation of a test bed consisting of precipitation sensor, flow velocity sensor, flow level sensor, camera sensor and a temperature sensor connected to a programmable nodes via a data acquisition board. These nodes are used to send the sensors' readings to the gateway. We have used the NI WSN-3212 and WSN-3202 for telemetered sensors and the NI WSN-3230 for visual sensors as programmable nodes for the WSN architecture. The gateway is an NI-WSN9795 module installed in cRIO chassis acts as the network coordinator, responsible for configuring all distributed nodes and collecting measured data from all of them. The measured are sent remotely to the central supervisory station where the data are analyzed and evaluated to predict the degree of dangerous of the valley and the flood places that will be alerted. The flood estimation server and the inverse modeling server require a dynamical model of the flood propagation. The used models is in the form of St Venant equations/ shallow water equations, or can be other hydrological models. The models require the definition of the landscape (terrain type, altitude isolines). The system can use any type of weather information such as: satellite weather nowcast, weather forecasts, weather precipitation data, and the proposed WSN real-time rain gauge measurements. Higher resolution of these feeds will improve the accuracy of flood maps, to a certain extent. A variety of WSN setups have been deployed and different test situations created to validate the proposed system and judge its performance. Presented simulations are based on previous flooding events to better calibrate the model parameters and thus increase the accuracy of the real-time forecast. However, the application of any hydrological model requires a validation process to make sure that the results are in an acceptable range. Unfortunately, flood data was not available for validation; therefore, a video record of the flood was used to extract flood records for the selected flood event (13 April 2016). The selected storm event was extremely short and heavy (fig 2 and Fig 3). Field control point The downstream control point is located at wadi Aljury, which is the longest wadi crossing the city of Banimalek. As the study area is characterized by a semi-arid climate at the higher mountain of Jazan, the culverts and bridges in the city of Jazan (Banimalek) are primarily made to prevent ephemeral flash flood events. Figure 3 shows The distribution of the computed rainfall total in the proposed model. It shows two highinstantaneous precipitation rates, one is equal to $180 \mathrm{~mm} / \mathrm{hr}$ at $01 \mathrm{~h} 45$, and the other is around $120 \mathrm{~mm} / \mathrm{hr}$ at $01 \mathrm{~h} 15$. As for the accumulated rainfall, the same sudden increase the threshold between $02 \mathrm{~h} 15$ and $03 \mathrm{~h}$ is shown in Figure 4. The accumulated rain smoothly increased after one hour. Importantly, the model performed well in the prediction of the maximum precipitation that was responsible for this flash flood event.

Another advantage of the proposed system is that it remotely acquires data of absolute water elevations, which is helpful for the early warning system of flood management. The cross section of the wadi at the bridge site was measured at a point, with the average width at $50 \mathrm{~m}$ and the average depth at 3.8 $\mathrm{m}$. The steps of measuring flow velocities and depth changes from special installed sensors. Figure 4 present the water level and the water velocity, it shows that the level exceeds the threshold at time $4 \mathrm{~h} 15$. The water exceeds the level after 2 hours from the time at which the accumulation rainfall rises the threshold limit. Importantly, the model performed well in the prediction of the maximum precipitation that was responsible for this flash flood event before 2 hours that the water level exceeds the threshold.

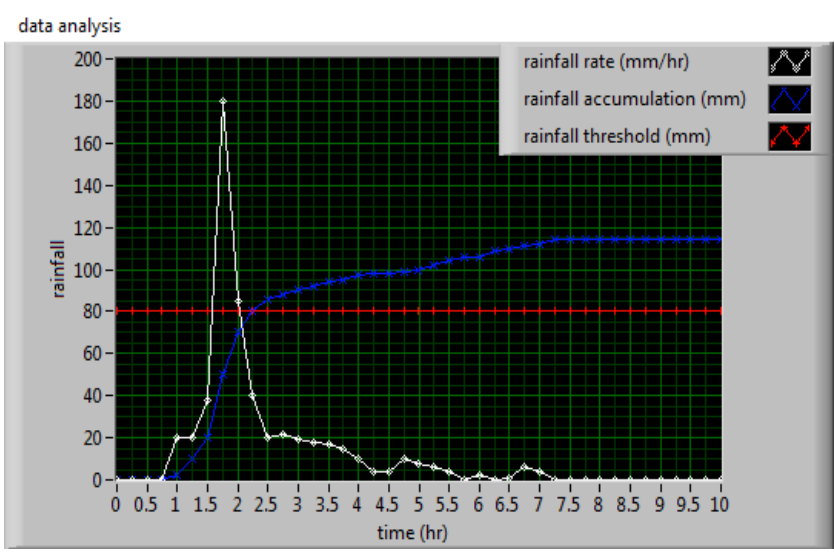

Fig 2. Rainfall storm information over the city of Jazan (Banimalek) for the particular flood event in zone 1

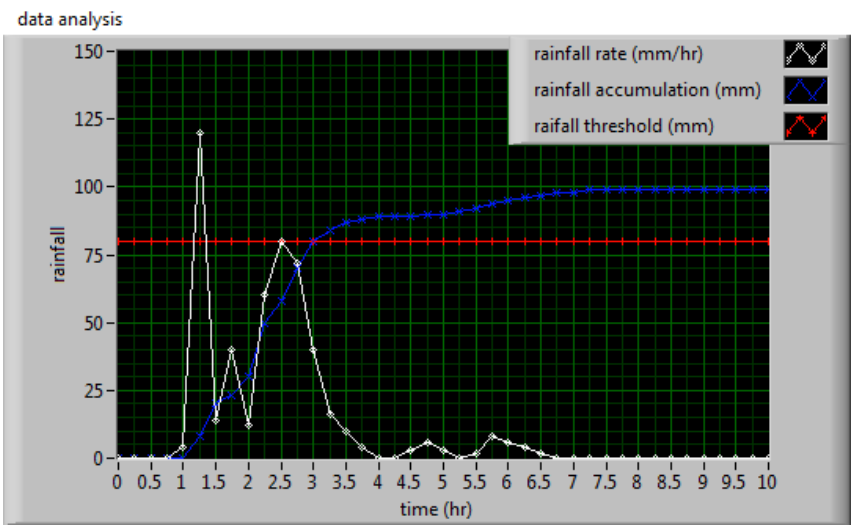

Fig 3. Rainfall storm information over the city of Jazan(Banimalek) for the particular flood event in zone 2 


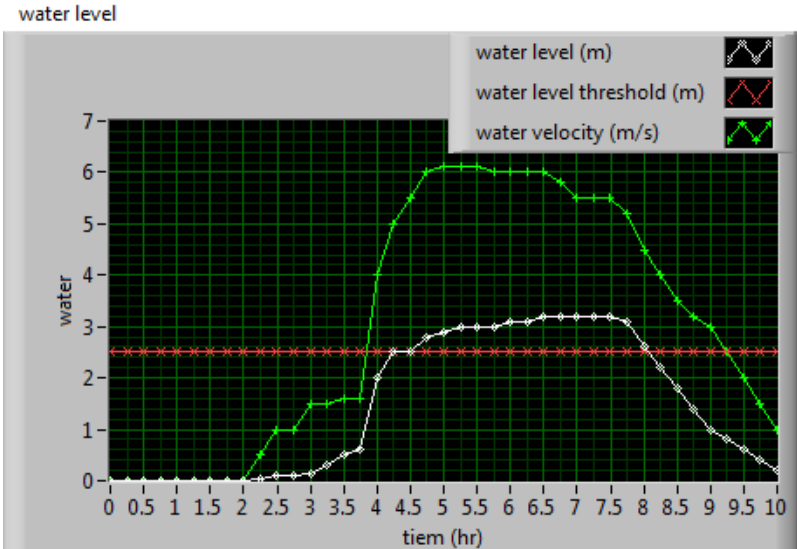

Fig 4. water level and velocity information over the city of Jazan (Banimalek) for the particular flood event ( 13 April 2016)

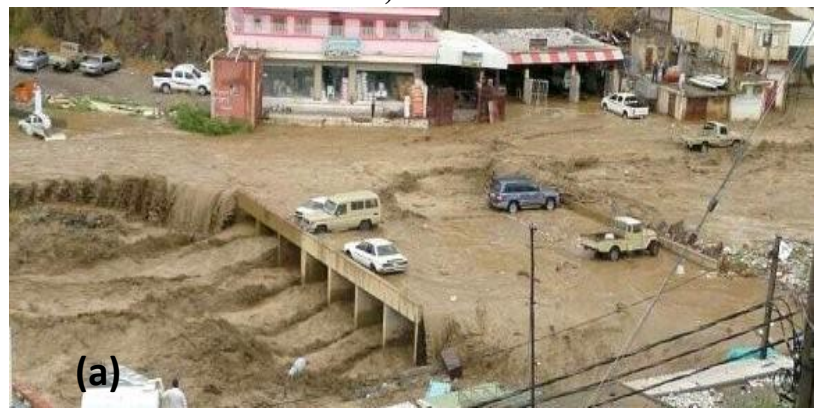

The video imagery technique was used to observe flood events for the date of 13 April 2016. Video images were recorded from a second bridge (Fig. 5) using a camera sensors. The camera records video at 60 images per second with a grid spacing of 35 pixels. Figure 5 (a) shows that the torrents exceeds the bridge at the beginning of the flood event. Moreover figure 5(b) shows the same place but at the top of the flood event where the red lines indicate the bridge. These images shows the evolution of the flash flood in the affected zone. In this type of analysis, hydrological data such as water level and precipitation from monitoring stations is combined with remote measurement images and geographic models to analyze and simulate flood events. In this way, this analysis derives risk information from a probabilistic viewpoint, which can be assessed with regard to various scenarios such as potential flood depth and coverage within a certain geographic area, and it provides flood risk assessment and risk mapping to identify zones that are vulnerable to flooding in advance.

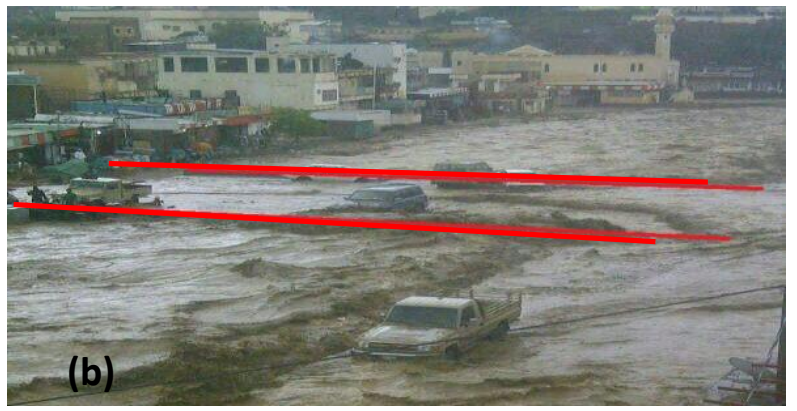

Fig 5. Video records at Wadi aljury (Banimalek, Jazan) in the flash flood event (a) at the beginning, (b) at highest degree of the flash flood event where the red lines show the bridge

\section{CONCLUSION}

The proposed system is to warn communities of the incoming flood and provide an effective solution by giving people sufficient time to evacuate and protect their property. An efficient flood early warning system requires the use of an automated system for data acquisition, analysis and the issuing of real-time warnings in the case of the prediction of flash flood and torrents occurrence. The presented results show that the proposed model is an important tool to predict the flash flood event, the dangerous degree and to identify the affected zone beforehand. It was mentioned that this model uses geographic models and hydrological model. The carried model can efficiently prioritize the high risk flooded areas and provide detailed information for assessing further needs. In the proposed system, hydrological data such as water level and precipitation are combined with remote measurement images and geographic models to analyze and simulate flood events. In this way, analysis extract risk information which can be assessed with regard to various scenarios such as potential flood depth and coverage within a certain geographic area, and it provides flood risk assessment and risk mapping to identify zones that are vulnerable to flooding in advance. Monitoring and evaluation of flash flood events based on the implemented model can help to constantly improve flood risk management plans and allow the identification of best practices under the specific circumstance. The obtained results from historical flood in the higher mountain of Jazan ( Wadi banimalek) can validate the proposed model. it is a useful tool to predict flooded area and to early alert people to protect from torrents dangerous.

\section{ACKNOWLEDGMENTS}

The author would like to acknowledge the financial support for this work from the Deanship of Scientific Research (DSR), Jazan University, Saudi Arabia, under grant no 4251.

\section{REFERENCES}

[1] H. Hasanean, M.Almazroui, Rainfall: Features and Variations over Saudi Arabia, A Review, Climate 2015, 3, 578-626; doi:10.3390/cli3030578.

[2] J-B. Williams, M. Shobrak, T-M. Wilms, I-A. Arif, H-A. Khan, Climate change and animals in Saudi Arabia, Saudi Journal of Biological Sciences (2012) 19, 121130.

[3] M. Almazroui, Simulation of present and future climate of Saudi Arabia using a regional climate model (PRECIS), Int. J. Climatol. 33: 2247-2259 (2013).

[4] M. Almazroui, M. Nazrul Islam, P.D. Jones, H. Athar, M. Ashfaqur Rahman, Recent climate change in the Arabian Peninsula: Seasonal rainfall and temperature climatology of Saudi Arabia for 1979-2009, Atmospheric Research 111 (2012) 29-45.

[5] M. Abdelkader, M. Shaqura, C-G. Claudel, W. Gueaieb, A UAV based system for real time flash flood monitoring in desert environments using Lagrangian microsensors, 2013 International Conference on Unmanned Aircraft Systems (ICUAS) May 28-31, 2013.

[6] V. Seal, A. Raha, S. Maity, S. Kr Mitra, A. Mukherjee, M. Kanti Naskar," a simple flood forecasting scheme using wireless sensor networks", International Journal of Ad 
hoc, Sensor \& Ubiquitous Computing (IJASUC) Vol.3, No.1, February 2012.

[7] R. Marin-Perez, J. Garcia-Pintado, A. Skarmeta Gomez, "A Real-Time Measurement System for Long-Life Flood Monitoring and Warning Applications", Sensors 2012, 12, 4213-4236; doi:10.3390/s120404213.

[8] S. Keoduangsine, R. Goodwin, "A GPRS-Based Data Collection and Transmission for Flood Warning System: The Case of the Lower Mekong River Basin", International Journal of Innovation, Management and Technology, Vol. 3, No. 3, June 2012.

[9] S-A. AlHassoun, Developing an empirical formulae to estimate rainfall intensity in Riyadh region, Journal of King Saud University - Engineering Sciences (2011) 23, 81-88.

[10] A. Samman, Numerical simulation diagnostics of a flash flood event in jeddah, saudi arabia, Thesis, Colorado State University, Fort Collins, Colorado, Spring 2014.

[11] L. Alfieri, J. Thielen, F. Pappenberger, Ensemble hydrometeorological simulation for flash flood early detection in southern Switzerland, Journal of Hydrology 424-425 (2012) 143-153.

[12] T-H. Yang, S-C. Yang, J-Y. Ho, G-F. Lin, Gong-Do Hwang, Cheng-Shang Lee, Flash flood warnings using the ensemble precipitation forecasting technique: A case study on forecasting floods in Taiwan caused by typhoons, Journal of Hydrology 520 (2015) 367-378.

[13] I. Jamil, R. Jamil, Z. Jinquan1, L. Ming, R. Jamil, Applied analysis and construction of Prevention, Monitoring and Early Warning System of Mountain Torrent Disaster, International Journal of Innovation and Applied Studies, ISSN 2028-9324 Vol. 4 No. 2 Oct. 2013, pp. 298-310.

[14] S-S. Mane, M-K.Mokashi, Real-Time Flash-Flood Monitoring, Alerting and Forecasting System using Data Mining and Wireless Sensor Network, IEEE ICCSP, 1881 - 1886, 2015.

[15] M. Sheik Dawood, J. Suganya, R. Karthika Devi, G. Athisha, "A Review on Wireless Sensor Network Protocol for Disaster Management", International Journal of Computer Applications Technology and Research, Vol.2, No.2, 141-146, 2013

[16] Degrossi et al," Wireless Sensor Networks for Flood Monitoring in Brazil:, Proceedings of the $10^{\text {th }}$ International ISCRAM Conference, Baden-Baden, Germany, May 2013.

[17] J. Sunkpho, C. Ootamakorn, "Real-time flood monitoring and warning system", Songklanakarin J. Sci. Technol. 33 (2), 227-235, Mar. - Apr. 2011.

[18] V.V. Krzhizhanovskaya, G.S. Shirshov, N.B. Melnikova, R.G. Belleman, F.I. Rusadi, B.J. Broekhuijsen, B.P. Gouldby, J. Lhommed, B. Balis, M. Bubak, A.L. Pyayt, I.I. Mokhov, A.V. Ozhigin, B. Lang, R.J. Meijer, Flood early warning system: design, implementation and computational modules, Procedia Computer Science 4 (2011) 106-115.

[19] V. Tejaswitha1, M. Jagadeesh Babu, Monitoring of Water Level Variations in Rivers and Flood Alert System Using Wireless Sensor Networks, International Research
Journal of Engineering and Technology (IRJET), Vol.03, No.07, 2016.

[20] S-W. Lo, J-H. Wu 1, F-P. Lin, C-H. Hsu, Visual Sensing for Urban Flood Monitoring, Sensors 2015, 15, 2000620029; doi:10.3390/s150820006.

[21] I. Elkhrachy, Flash Flood Hazard Mapping Using Satellite Images and GIS Tools: A case study of Najran City, Kingdom of Saudi Arabia (KSA), The Egyptian Journal of Remote Sensing and Space Sciences (2015) $18,261-278$

[22] M. Almazroui, Calibration of TRMM rainfall climatology over Saudi Arabia, during 1998-2009, Atmospheric Research 99 (2011) 400-414.

[23] A-E. Tekeli, H. Fouli, Evaluation of TRMM satellitebased precipitation indexes for flood forecasting over Riyadh City, Saudi Arabia, Journal of Hydrology (2016) Vol.541 Part A, 471-479

[24] L. Alfieri, P. Salamon, F. Pappenberger, F. Wetterhall, J. Thielen, Operational early warning systems for waterrelated hazards in Europe, environmental science \& policy 21 (2012) 35-49.

[25] L. Alfieri, and J. Thielen, A European precipitation index for extreme rain-storm and flash flood early warning, Meteorol. Appl. 22: 3-13 (2015).

[26] N-N. Kourgialas, G-P. Karatzas, Flood management and a GIS modelling method to assess flood-hazard areas-a case study, Hydrological Sciences Journal, 56(2) 2011.

[27] L. Alfieri1, D. Velasco, J. Thielen, Flash flood detection through a multi-stage probabilistic warning system for heavy precipitation events, Adv. Geosci., 29, 69-75, 2011.

[28] M.Haq, M. Akhtar, S. Muhammad, S. Paras, J. Rahmatullah, Techniques of Remote Sensing and GIS for flood monitoring and damage assessment: A case study of Sindh province, Pakistan, the Egyptian Journal of Remote Sensing and Space Sciences (2012) 15, 135-141.

[29] M. Erdelj, E. Natalizio, UAV-Assisted Disaster Management: Applications and Open Issues, International Workshop on Wireless Sensor, Actuator and Robot Networks, 2016.

[30] D. Popescu, L. Ichim, T. Caramihale, Flood Areas Detection Based on UAV Surveillance System, 19th International Conference on System Theory, Control and Computing (ICSTCC), October 14-16, 2015.

[31] J-K. Roy, D. Gupta, S. Goswami, An Improved Flood Warning System using WSN and Artificial Neural Network, India Conference (INDICON), 7-9 Dec. 2012.

[32] M-A. Islam, T. Islam, M-A. Syrus, N. Ahmed, Implementation of Flash Flood Monitoring System Based on Wireless Sensor Network in Bangladesh, $3^{\text {rd }}$ International conference on informatics, electronics \& vision 2014

[33] E-N. Udo, E-B. Isong, Flood Monitoring and Detection System using Wireless Sensor Network, Asian Journal of Computer and Information Systems, Vol.01, No.04, 2013.

[34] H-C. Yang1, C-C. Su, Real-time river bed scour monitoring and synchronous maximum depth data 
collected during Typhoon Soulik in 2013, Hydrol. Process. 29, 1056-1068 (2015).

[35] O. Saitou ,Y. Kuwahara, M. Niibori, M. Kamada, RealTime Water Level Visualization with Pervasive IC Sensors, $16^{\text {th }}$ International Conference on NetworkBased Information Systems, 2013.

[36] J-A. Hernandez-Nolasco, M-A. Wister, F-D. Acosta, P. Pancardo, Water Level Meter for Alerting Population about Floods, IEEE $30^{\text {th }}$ International Conference on Advanced Information Networking and Applications, 2016.

[37] M. Mousa, X. Zhang, C. Claudel, Flash Flood Detection in Urban Cities Using Ultrasonic and Infrared Sensors, IEEE Sensors Journal, Vol. 16, No. 19, October 1, 2016.

[38] D-w. Zhang, J. Quan, H-b. Zhang, F. Wang, H. Wang, XY. He, Flash flood hazard mapping: A pilot case study in Xiapu River Basin, China, Water Science and Engineering 2015, 8(3).

[39] C. Li, B. Xu, T. Fan, H. Wang, Y. Gu, Flash Flood Monitor and Early Warning Platform Design Based on Numerical Simulation, Remote Sensing, Environment and Transportation Engineering (RSETE), 2012 2nd International Conference on, 1-3 June 2012.

[40] J. Cools, P. Vanderkimpen, G. El Afandi, A. Abdelkhalek, S. Fockedey, M. El Sammany, G. Abdallah, M. El Bihery, W. Bauwens5, and M. Huygens, An early warning system for flash floods in hyper-arid Egypt, Nat. Hazards Earth Syst. Sci., 12, 443-457, 2012.

[41] A.Dersingh, Design and Development of a Flood Warning System via Mobile and Computer Networks,
International Conference on Electronics, Information, and Communications (ICEIC), 27-30 Jan. 2016.

[42] S. Shiravale, P. Sriram, S-M. Bhagat, Flood Alert System by using Weather Forecasting Data and Wireless Sensor Network, International Journal of Computer Applications (0975 - 8887) Vol.124, No.10, 2015.

[43] J-L. Gomes, G. Jesus, J. Rogeiro, A. Oliveira, R-T. da Costa, A-B. Fortunato, Molines - towards a responsive Web platform for flood forecasting and risk mitigation, Proceedings of the Federated Conference on Computer Science and Information Systems pp. 1171-1176, 2015.

[44] X.Li, X. Cheng, P. Gong, K. Yan, Design and Implementation of a Wireless Sensor Network-Based Remote Water-Level Monitoring System, Sensors 2011, 11, 1706-1720; doi:10.3390/s110201706.

[45] R. Marin-Perez, J. Garcia-Pintado, A-S. Gomez, A RealTime Measurement System for Long-Life Flood Monitoring and Warning Applications, Sensors 2012, 12, 4213-4236; doi:10.3390/s120404213.

[46] S. Debbarma, FPGA implementation of flood monitoring system, national institute of technology ,Rourkela, Odisha, India, 2014.

[47] E. Abushandi, Flash flood simulation for Tabuk City catchment, Saudi Arabia, Arab J Geosci (2016) 9: 188, DOI 10.1007/s12517-015-2192-x

[48] N. Ahmad, M. Hussain, N. Riaz, F. Subhani, S. Haider, K-S. Alamgir, Fahad Shinwari, Flood Prediction and Disaster Risk Analysis using GIS based Wireless Sensor Networks, A Review, J. Basic. Appl. Sci. Res., 3(8)632643, 2013. 